\title{
FUNCTIONAL AND RADIOLOGICAL OUTCOME OF POSTERIOR COLUMN FRACTURE FIXATION IN TIBIAL PLATEAU FRACTURES- A CASE SERIES
}

\author{
P. V. Pugalenthi' ${ }^{1}$ R. Sivakumar', T. C. Prem Kumar ${ }^{3}$, K. Senthil Kumar 4
}

1 Professor and HOD, Department of Orthopaedics and Traumatology, Madurai Medical College, Madurai, Tamilnadu.

2 Professor, Department of Orthopaedics and Traumatology, Madurai Medical College, Madurai, Tamilnadu.

3 Senior Assistant Surgeon, Department of Orthopaedics and Traumatology, Madurai Medical College, Madurai, Tamilnadu.

${ }_{4}^{4}$ Postgraduate Student, Department of Orthopaedics and Traumatology, Madurai Medical College, Madurai, Tamilnadu.

\begin{abstract}
\section{BACKGROUND}

Posterior tibial plateau fractures are unstable fractures, which should to be fixed for anatomical reduction and better clinical outcome following surgical intervention and Luo 3 column classification is effective in identification of fractures and preoperative planning. Posterior plate osteosynthesis using posterior approach in supine or prone position were used alone or in combination with anterolateral plate osteosynthesis or cancellous screw fixation as per the fractures configuration for fixation. Patients were followed up by using modified Rasmussen clinical and radiological criteria.

Aims and Objectives- To evaluate the results of posterior plate osteosynthesis for displaced tibial plateau fractures.
\end{abstract}

\section{MATERIALS AND METHODS}

10 patients with tibial plateau fractures with posterior column involvement were included in the study. 10 patients ( 9 males and 1 female) with tibial plateau fractures with posterior column involvement (Luo 3 column classification: 1 column- 3 patients, 2 column- 3 patients, 3 column- 4 patients) were treated by posterior plate osteosynthesis alone or combined with screw/anterolateral plate osteosynthesis according to the fracture morphology between Sep 2015 and Aug 2017. Functional and radiological outcome was assessed using modified Rasmussen's clinical and radiological criteria.

\section{RESULTS}

All 10 patients ( 9 males and 1 female) are classified according to Luo 3 column classification ( 1 column- 3 patients, 2 column- 3 patients, 3 column- 4 patients) with mean follow-up of 13.7 months. None of them developed varus collapse and all fractures were united within 3 to 4 months. One patient developed deep wound infection and was treated by flap cover. Clinical and radiological outcome was excellent in $40 \%$ and good in $60 \%$ of the patients.

\section{CONCLUSION}

Posterior plate osteosynthesis improve the strength and stiffness of posteromedial fragment fixation and had a buttress effect preventing descent of the fragment under load and reduce the varus collapse and increase in range of movements with minimal soft tissue complications if surgery is done after soft tissue condition improves.

\section{KEY WORDS}

Tibial Plateau Fracture, Posterior Plate, 3 Column Fracture.

HOW TO CITE THIS ARTICLE: Pugalenthi PV, Sivakumar R, Kumar TCP, et al. Functional and radiological outcome of posterior column fracture fixation in tibial plateau fractures- a case series. J. Evolution Med. Dent. Sci. 2018;7(21):2638-2643, DOI: $10.14260 /$ jemds/2018/592

\section{BACKGROUND}

Tibial plateau fractures are one of the commonest periarticular fractures. These fractures include $1 \%$ of all fractures and $8 \%$ of fractures in elderly. Motor vehicle accidents account for the majority of these fractures in younger individuals with good bone stock, but in elderly individuals these fractures may result from simple fall due to osteopenic bone.

These fractures are associated with high energy violence and extensive soft tissue injury. Each fracture type has its own morphology, treatment considerations and prognosis.

'Financial or Other Competing Interest': None.

Submission 28-02-2018, Peer Review 05-05-2018,

Acceptance 12-05-2018, Published 21-05-2018.

Corresponding Author:

K. Senthil Kumar,

No. 617, Oasis Hotel,

Madurai Medical College,

Madurai, Tamilnadu.

E-mail: grhorthosenthil@gmail.com

DOI: $10.14260 /$ jemds $/ 2018 / 592$

\section{(c) $(1)$}

Apart from bony injury, meniscal tear and ligament injuries should also be assessed. Over the past 50 years, management of tibial plateau fractures has completely changed from conservative to surgical management with anatomical reduction and fixation.

Nevertheless, management of tibial plateau fractures remain challenging because of their varied pattern, associated soft tissue and ligament injury, varying opinions regarding surgical management including various or 3 column fixation for fractures of tibial plateau exits.

Conservative methods may result in malunion and articular congruity cannot be restored. Surgical treatment can regain articular congruity and restore mechanical alignment and can allow early range of motion. Open reduction and internal fixation techniques had been associated with wound complications. This has led to the emergence of alternate methods such as Ilizarov ring fixation, external fixation with limited internal fixation and hybrid external fixation. Achieving good reduction and stable fixation sparing knee joint was not possible with external fixation. ${ }^{1}$ 
Rigid fixation with good articular congruity is the goal of surgery to get good knee function. ${ }^{2}$ Open reduction and internal fixation achieves this goal. Open reduction and internal fixation can be achieved by various approaches including- Mercedes Benz, anterolateral, posterolateral, anteromedial, single anterior midline incisions, posteromedial, posterolateral and posterior approaches.

Fracture reduction can be achieved either by single (Mercedes Benz, Single anterior midline) or double (anterolateral and posteromedial) incisions. Study conducted by Raykov et al stated that Mercedes Benz incision had high rates of wound necrosis. ${ }^{3}$ Tibial plateau fractures are managed with single anterolateral or dual plating. In high energy tibial plateau fractures involving posteromedial fragment, dual plating is better than the single plating.

To achieve satisfactory fixation of the tibial plateau fractures it is mandatory to know the fracture morphology, soft tissue and ligament status of the injury.

Luo CF et al stated three column classification concept provides excellent inter-observer reliability than conventional Schatzker classification and AO/OTA classification and allows better understanding of the fracture morphology and detection of posterior column fractures which guides in preoperative planning. $4,5,6$

Supine position ${ }^{7,8}$ and in multiplanar fractures involving the posterior column and combination of posterior and anterior-lateral approaches is a safe and effective way to have direct reduction and satisfactory fixation in supine or combined supine and prone positions. ${ }^{9}$ Intraoperative repositioning of patient, skin preparation and draping is time consuming and prolongs surgical time, thus dual plate fixation in supine position can also be done.10

\section{MATERIALS AND METHODS}

In our institution, 10 patients with displaced tibial plateau fractures with posterior column involvement were selected for the study. This is a case series study done from September 2015 to August 2017.

Mode of injury was road traffic accident in all 10 patients. Patients were evaluated with $\mathrm{x}$-rays (AP and lateral views) and Computed Tomography (axial, coronal and sagittal with 3D reconstruction views). Fractures were classified based on 3 column concept classification. Mean follow-up period was 13.7 months (6 - 21 months). Functional and radiological outcome was assessed using Modified Rasmussen's clinical and radiological criteria.

\section{Study Design}

Case Series.

\section{Inclusion Criteria}

- Fractures with posterior column involvement.

- Closed injury.

- $\quad$ Age more than 18 years.

\section{Exclusion Criteria}

- Associated head/ chest/ abdomen/ pelvis/ spine injury.

- Patient below 18 years of age.

- $\quad$ Patient not fit for surgery and not willing for surgery.

\section{Pre-operative Evaluation}

- X-ray knee AP view, lateral view.

- $\quad$ CT knee with 3D reconstruction.

- HB, blood sugar, urea, creatinine, viral markers, electrocardiogram for anaesthetic assessment.

\section{Implants and Instruments}

- Proximal tibial locking plates.

- T/L buttress plates.

- Posteromedial and posterior tibial locking plate.

\section{Surgery}

- Posteromedial plate osteosynthesis.

- Posterior plate osteosynthesis.

- Posterolateral plate osteosynthesis.

Combined with anterolateral plate osteosynthesis if necessary as per fracture configuration.

\section{Anaesthesia}

Regional/ Spinal anaesthesia was used in all patients.

\section{Position}

Supine position or prone position depend on the approach used to fix the fracture.

\section{Surgical Technique ${ }^{8,9,10}$}

After careful preoperative evaluation, the fracture morphology surgical approach and patient position planned. In our study, posteromedial plate osteosynthesis was done in both supine and prone positions. Posterior plate osteosynthesis was done in prone position using Galla and Lobenhoffer approach. In combined posteromedial and anterolateral plate osteosynthesis for 3 column fracture cases patient was positioned in supine-

- After inflation of high thigh tourniquet.

- In supine position: Open interval between posterior Pes anserinus and medial gastrocnemius and avoid saphenous vein and nerve.

- In prone position: Open interval between semitendinosus complex and gastrocnemius medial head and protect saphenous nerve, great saphenous vein, popliteal vessels and tibial nerves.

- Expose the posteromedial tibia subperiosteally.

- Place retractor along posterior tibia to protect popliteal fossa structures.

- Apply reduction clamp with manual traction and manipulation.

- $\quad$ Reduce fracture and fix provisionally with K-wire.

- Confirm reduction of fracture and overall joint alignment fluoroscopically.

- $\quad$ Fix with antiglide plate for buttressing the fracture and interfragmentary screws through upper hole of the plate if necessary.

Posterior column fixed first with antiglide plate using $\mathrm{T} / \mathrm{L}$ buttress or $3.5 \mathrm{~mm}$ locking posterior or posteromedial plates with minimal screws in posterior column fracture alone. Posteromedial plate osteosynthesis combined with subsequent anterolateral plate osteosynthesis with proximal tibial locking plate in 2 or 3 column fractures. 


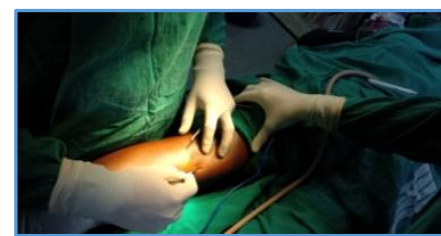

Incision

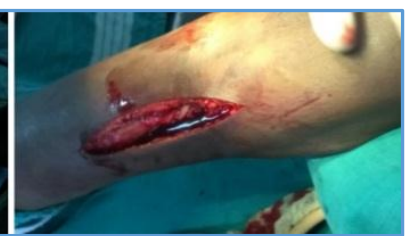

Superficial Dissection

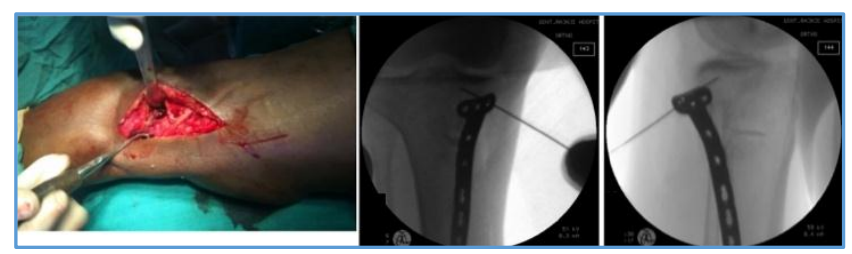

Deep Dissection C-Arm Picture with Provisional K Wire

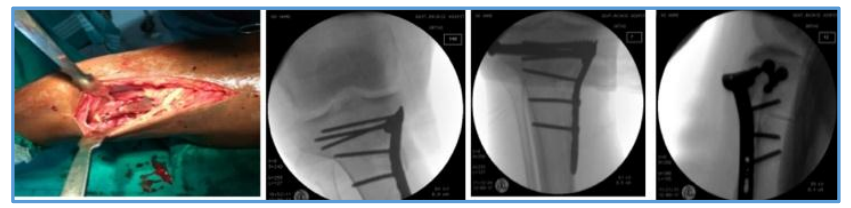

C-Arm Picture after Antiglide Plate and Screw Fixation

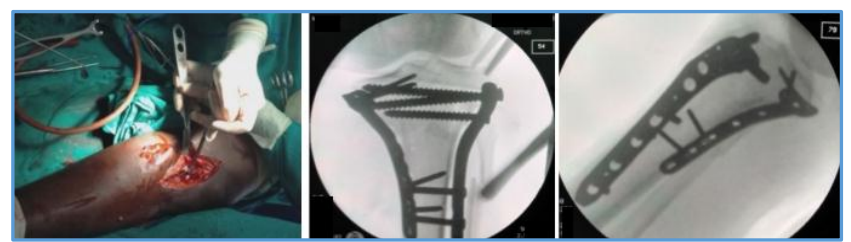

Intraoperative Picture in Supine Position in Posteromedial and Anterolateral Plate Osteosynthesis

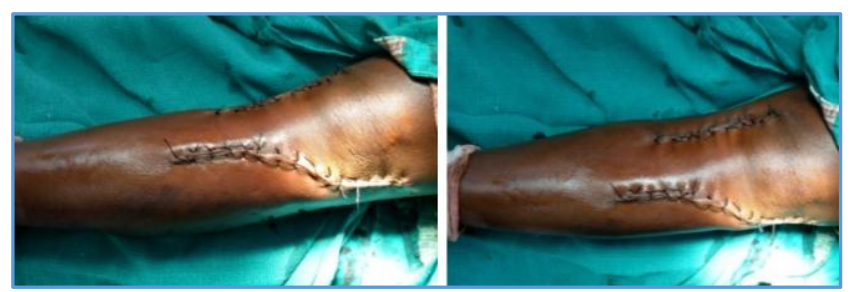

After Skin Closure

In our study, all the 3 column fractures are treated with dual plating with posteromedial and anterolateral plate fixation in supine position. Single posterior column fracture fixed with posterior plate and double column fixation done with posterior/ posteromedial plate fixation with $6.5 \mathrm{~mm}$ cancellous screw fixation or anterolateral plate fixation in supine or prone position as per the fracture morphology and surgeon's preference. One patient with anterior tibial spine fracture Meyer's and McKeever's type I with single column fracture fixed with posterior plating and tibial spine fracture treated conservatively.

\section{Postoperative Follow-Up}

Patients were treated with IV antibiotics for 5 days postoperatively. EOT was done on POD 2, 5, 8 and POD 10. Sutures removal was done on POD 12.

Patients were mobilised as early as possible. Ankle pump and quadriceps exercises were performed from second POD. Knee bending exercises were started after the pain subsided and as tolerated by the patient.
Partial weight bearing using walkers started after 6 weeks and full weight bearing was allowed after $3-4$ months depending upon the union of the fracture site. Physical therapy was continued until range of motion and muscle strength was regained.

Postoperatively, patients were evaluated with x-ray AP and lateral views at 6 weeks, 6 months and 1 year.

Functional and radiological outcomes were assessed by Modified Rasmussen's clinical and radiological criteria.

\section{Functional Outcome}

The functional outcome was assessed with Modified Rasmussen's clinical criteria, which includes pain (Maximum points- 6), working capacity (Maximum points- 6), knee extension (Maximum points- 4), range of motion (Maximum points- 6), stability (Maximum points- 6) and power of quadriceps (Maximum points- 2) with maximum total points- 30. Results were graded as excellent (28 - 30), good (24 - 27), fair (20 - 23) and poor $(<20)$.

\section{Radiological Assessment}

Radiological outcome was assessed with Modified Rasmussen's radiological criteria at the end of 6 months. Criteria includes articular depression (Maximum points- 3), condylar widening (Maximum points- 3), varus or valgus angulation (Maximum points- 3) and osteoarthrosis (Maximum point- 1). Results were graded as excellent (9$10)$, good $(7-8)$, fair $(5-6)$ and poor $(<5)$.

\section{RESULTS}

10 patients with tibial plateau fractures with displaced posterior column fractures admitted at Government Rajaji Hospital, Madurai were included in this study. All the patients were treated with posterior plating with or without additional anterolateral plating in supine or prone position was done after assessing fracture morphology with CT scan and three column classification and surgeon's preference on positioning the patients. The longest follow-up period was 21 months and shortest follow-up period was 6 months. Mean follow-up period was 13.7 months. Follow-up analysis was made using Modified Rasmussen's Clinical and Radiological criteria.

In our study, $70 \%$ of the patients were in active productive age group (30 - 50 years). $90 \%$ of the patients were male. There was no significant difference in the side affected (Rt. side- 5 patients, Lt. side- 5 patients). All the patients in this study sustained injury due to road traffic accident. $30 \%$ of single column fractures (LUO)- Schatzker type IV 10\%, Hohl and Moore type I coronal split fracture $20 \%, 30 \%$ of two column fracture (LUO) - Schatzker type IV $20 \%$, type V $10 \%, 40 \%$ of three column fractures (LUO) Schatzker type V $40 \%$ included.

In this study $40 \%$ patients had excellent outcome, $60 \%$ patients had good outcome.

In this study, one patient 68 years old male with 3 column fracture developed superficial blisters over the tibial plateau region and patient was taken into surgery after soft tissue healing and he developed wound infection post-operatively and treated by flap cover. 
Functional and Radiological Outcome

\begin{tabular}{|c|c|c|c|c|}
\hline $\begin{array}{c}\text { Modified } \\
\text { Rasmussen }\end{array}$ & $\begin{array}{c}\text { Functional- No. of } \\
\text { Patients }\end{array}$ & $\begin{array}{c}\text { Functional- } \\
\text { Percentage }\end{array}$ & $\begin{array}{c}\text { Radiological- No. of } \\
\text { Patients }\end{array}$ & $\begin{array}{c}\text { Radiological- } \\
\text { Percentage }\end{array}$ \\
\hline Excellent & 4 & 40 & 4 & 40 \\
\hline Good & 6 & 60 & 6 & 60 \\
\hline Fair & 0 & 0 & 0 & 0 \\
\hline Poor & 0 & 0 & 0 & 0 \\
\hline
\end{tabular}

\begin{tabular}{|c|c|c|c|c|c|}
\hline Age (Years) & Frequency & Percentage & Sex & Frequency & Percentage \\
\hline $20-30$ & 1 & 10 & & 9 & 90 \\
\hline $31-40$ & 2 & 20 & Male & 1 & 10 \\
\hline $41-50$ & 5 & 50 & Female & $\mathbf{1 0}$ & $\mathbf{1 0 0}$ \\
\hline $51-60$ & 1 & 10 & Total & Frequency & Percentage \\
\hline $61-70$ & 1 & 10 & Mode of Injury & 10 & 100 \\
\hline Total & $\mathbf{1 0}$ & $\mathbf{1 0 0}$ & Road traffic accident & $\mathbf{1 0}$ & $\mathbf{1 0 0}$ \\
\cline { 5 - 7 } & & Total & & \\
\hline
\end{tabular}

\begin{tabular}{|c|c|c|c|c|c|}
\hline Side & Frequency & Percentage & Fracture Type & Frequency & Percentage \\
\hline Right & 5 & 50 & Schatzker Type IV & 3 & 30 \\
\hline Left & 5 & 50 & Schatzker Type $\mathrm{V}$ & 5 & 50 \\
\hline Total & 10 & 100 & Moore Type I & 2 & 20 \\
\hline & & & Total & 10 & 100 \\
\hline
\end{tabular}

\begin{tabular}{|c|c|c|c|c|c|c|}
\hline $\begin{array}{l}\text { Three Column } \\
\text { Classification }\end{array}$ & Frequency & Percentage & & $\begin{array}{c}\text { Single } \\
\text { Column }\end{array}$ & $\begin{array}{c}\text { Two } \\
\text { Column }\end{array}$ & $\begin{array}{c}\text { Three } \\
\text { Column }\end{array}$ \\
\hline 1 & 3 & 30 & Schatzker Type IV & 1 & 2 & 0 \\
\hline 2 & 3 & 30 & Schatzker Type V & 0 & 1 & 4 \\
\hline 3 & 4 & 40 & Moore Type I & 2 & 0 & 0 \\
\hline & & & Total & 3 & 3 & 4 \\
\hline
\end{tabular}

\begin{tabular}{|c|c|c|c|c|c|c|c|}
\hline $\begin{array}{c}\text { Time Interval } \\
\text { (Days) }\end{array}$ & $\begin{array}{c}\text { No. of } \\
\text { Cases }\end{array}$ & $\mathbf{\%}$ & Position & $\begin{array}{c}\text { Posterior } \\
\text { Plating }\end{array}$ & $\begin{array}{c}\text { Posteromedial } \\
\text { Plating }\end{array}$ & $\begin{array}{c}\text { Posteromedial Plating } \\
\text { with Screw Fixation }\end{array}$ & $\begin{array}{c}\text { Dual (pm/al) } \\
\text { Plating }\end{array}$ \\
\hline $0-7$ & 3 & 30 & Supine & 0 & 1 & 1 & 4 \\
\hline $8-14$ & 5 & 50 & Prone & 2 & 1 & 1 & 0 \\
\hline $15-21$ & 2 & 20 & Total & $\mathbf{2}$ & $\mathbf{2}$ & & $\mathbf{2}$ \\
\hline Total & $\mathbf{1 0}$ & $\mathbf{1 0 0}$ & & & & & \\
\hline
\end{tabular}

\section{DISCUSSION}

Tibial plateau fractures, one of the commonest intraarticular fractures occurring as a result of RTA fall from height, violence etc. The management of these fractures has always been in debate, because of their variety of fracture pattern and soft tissue complications. High energy tibial plateau fractures have associated with more severe fracture pattern, ligament injury and severe soft tissue injuries. Bicondylar fractures are best treated with dual plating than single lateral plating with better anatomic reduction and rigid fixation and it also has soft tissue complications as well. There are many approaches for fixation of tibial plateau fractures, each one has its own merits and demerits. Selection of approach and fixation for tibial plateau fractures is still a debate for better outcomes.

In high energy tibial plateau fractures, posteromedial and posterior fractures are often not able to fix with anterolateral plate alone. Fractures of the posterior tibial plateau are not uncommon, especially in high-energy trauma.11 Fixation of posteromedial and posterolateral fractures are essential in obtaining excellent clinical and radiological outcome in the high energy tibial plateau fractures. Failure to fix the posteromedial fragment result in varus collapse and decreased range of motion and clinical outcome in displaced tibial plateau fractures and posterior tibial fractures are best studied and planned for fixation using the three column fixation proposed by Luo CF et al.
Posteromedial or posterior approaches either in prone or supine provides better visualisation of the fractures and aid in better reduction and fixation and it also has the advantages of less soft tissue injury even when combined with anterolateral incision and it can also be used to fix the posterior cruciate ligament injury if present. Posterior column fixation through these approaches with antiglide plate and medial and lateral column fixation with screws or lateral locking plates provides the accurate reduction of articular surfaces and rigid fracture fixation, thereby has advantages of early mobilisation, reduced soft tissue complications, better range of movements, early mobilisation than other modes of fixations.

In our period of study 374 patients were admitted with tibial plateau fractures in our institution, 71 cases were treated with open reduction and internal fixation, out of which 10 cases were taken into study for posterior plate fixation who fits into the inclusion criteria.

In this study, functional and radiological outcome in displaced tibial plateau fractures with posterior column involvement of 10 patients were treated by posterior plate osteosynthesis with antiglide plating with interfragmentary screws through the upper hole of the antiglide plate if needed and it was combined with or without lateral support with $6.5 \mathrm{~mm}$ cancellous screws or plate osteosynthesis. Plateau fractures were studied with CT scan and classified and planned for approach and plating using three column 
classification. Postoperative functional and radiological outcome was assessed by using Modified Rasmussen Criteria.

In this study, tibial plateau fractures were more commonly seen in the active productive age group (31 - 50 years) due to high-energy trauma. Conservative management, external fixators and routine anterolateral plate osteosynthesis are difficult to reduce and fix the posterior column fractures, especially in posteromedial fragment and coronal splitting Moore type I fractures. It is extremely important to adequately visualise the fragments, reduce the fracture, regain articular congruity and obtain stable rigid fixation.

In our series, majority of patients were male (90\%) as they were involved mostly in road traffic accidents due to their occupation. There was no significant difference in the side affected in this study (right- 5 , left- 5 patients).

In our study, three column classification utilised to evaluate the fracture morphology and to plan for fracture fixation. Fracture distribution in our study was $30 \%$ of single column fractures (Schatzker type IV 10\%, Hohl and Moore type I coronal split fracture 20\%), 30\% of two column fracture (Schatzker type IV 20\%, type V 10\%), 40\% of three column fractures (Schatzker type V 40\%) included.

In this study, one patient 68 years old male with 3 column fracture developed superficial blisters over the tibial plateau region and patient was taken into surgery after soft tissue healing and he developed wound infection post-operatively and treated by flap cover.

Soft tissue complications are a major concern in the treatment of bicondylar tibial plateau fractures with plates. Papers reporting the results of DP through a single extensile incision have shown the incidence of deep wound infection of $23 \%-88 \% .12,13$ With the two incision DP technique, the incidence drops to $4.7 \%-8.4 \% .14,15$ With LISS fixation, it is reported to range from $0 \%$ to $22 \% .16,17,18$ In our study, one patient had deep infection (10\%) for which flap cover and comparing with other studies infection rate was little higher.

In a study conducted by Waddell et al, ${ }^{17}$ patients treated with single lateral plating developed varus malunion at the fracture site. Zheng18 et al stated that patients treated with dual plating provided better stability and none of the patients developed malunion. When comparing to the above studies, none of the patients developed malunion in our study. This clearly shows dual plating offers better stability than single lateral plating.

In a study conducted by Zhi et $\mathrm{al}^{19}$ West et $\mathrm{al}^{20}$ and Luo et al on tibia bone model, posteromedial T-plate can improve the strength and stiffness of posteromedial fragment fixation and had a buttress effect preventing descent of the fragment under load than other modes of fixation (Antero-posterior lag screws, an anteromedial limited contact dynamic compression plate (LC-DCP), a lateral locking plate). Hence, reduce the varus collapse and increase in range of movements by fixing the unstable posterior fragments. No patient developed varus collapse in our study.

In our study also, all the fractures were united between 3 to 4 months.

There was no neurovascular injury, no implant breakage, no varus valgus deformity, no delayed union or non-union in our study. $40 \%$ of the patients attained good and $60 \%$ excellent outcome in the follow-up study.

\section{Limitations of the Study}

Limitations of this study includes small sample size, shortterm follow-up, surgery done by different surgeons and all fractures included in this study was caused by road traffic accidents.

\section{CONCLUSION}

1. Posterior plate osteosynthesis of posterior column fracture fixation through posteromedial or posterior approach in either supine or prone position provides better visualisation and rigid fixation of posterior tibial fractures without major soft tissue complications if the surgery is done once the soft tissue condition improves.

2. In high energy displaced tibial plateau fractures of 3 column fractures can be treated with dual plating with conventional lateral locking plate or screw fixation when combined with posterior antiglide plating effectively.

3. Posterior plate osteosynthesis improves the strength and stiffness of posteromedial fragment fixation and had a buttress effect preventing descent of the fragment under load than other modes of fixation. Hence, reduce the varus collapse and increase in range of movements by fixing the unstable posterior fragments. Rigid anatomical fixation without much soft tissue complication allow the patient to mobilise early and increase range of movement and functional outcome.

To conclude, posterior plate osteosynthesis in displaced tibial plateau fractures with posterior column involvement resulted in good clinical and radiological outcomes.

\section{REFERENCES}

[1] Mallik AR, Covall DJ, Whitelaw GP. Internal versus external fixation of bicondylar tibial plateau fractures. Orthop Rev 1992;21(12):1433-6.

[2] Su EP, Westrich GH, Rana AJ, et al. Operative treatment of tibial plateau fractures in patients older than 55 years. Clin Orthop Relat Res 2004;421:240-8.

[3] Raykov D, Ivanov S, Apostolov P. Tibial plateau fractures - standard and specific surgical approaches. Scripta Scientifica Medica 2013;45(3):74-81.

[4] Yang G, Zhai Q, Zhu Y, et al. The incidence of posterior tibial plateau fracture: an investigation of 525 fractures by using a CT-based classification system. Arch Orthop Trauma Surg 2013;133(7):929-34.

[5] Zhu Y, Yang G, Luo CF, et al. Computed tomographybased three-column classification in tibial plateau fractures: introduction of its utility and assessment of its reproducibility. J Trauma Acute Care Surg 2012;73(3):731-7.

[6] Zhu Y, Hu CF, Yang G, et al. Inter-observer reliability assessment of the Schatzker, AO/OTA and threecolumn classification of tibial plateau fractures. J Trauma Manag Outcomes 2013;7(1):7.

[7] Lin KC, Tarng YW, Lin GY, et al. Prone and direct posterior approach for management of posterior column tibial plateau fractures. Orthop Traumatol Surg Res 2015;101(4):477-82. zzz 
[8] Galla M, Lobenhoffer P. The direct, dorsal approach to the treatment of unstable tibial posteromedial fracture-dislocations. Unfallchirurg 2003;106(3):2417. In German.

[9] Luo CF, Sun H, Zhang B, et al. Three-column fixation for complex tibial plateau fractures. J Orthop Trauma 2010;24(11):683-92.

[10] Chang SM, Wang X, Zhou JQ, et al. Posterior coronal plating of bicondylar tibial plateau fractures through posteromedial and anterolateral approaches in a healthy floating supine position. Orthopedics 2012;35(7):583-8.

[11] Brown GA, Sprague BL. Cast brace treatment for plateau and bicondylar fractures of the proximal tibia. Clin Orthop Relat Res 1976;119:184-93.

[12] Moore TM, Patzakis MJ, Harvey JP. Tibial plateau fractures: definition, demographics, treatment rationale and long-term results of closed traction management or operative reduction. J Orthop Trauma 1987;1(2):97-119.

[13] Young MJ, Barrack RL. Complications of internal fixation of tibial plateau fractures. Orthop Rev 1994;23(2):149-54.

[14] Stevens DG, Beharry R, McKee MD, et al. The long-term functional outcome of operatively treated tibial plateau fractures. J Orthop Trauma 2001;15(5):312-20.
[15] Egol KA, Su E, Tejwani NC, et al. Treatment of complex tibial plateau fractures using the less invasive stabilization system plate: clinical experience and a laboratory comparison with double plating. J Trauma 2004;57(2):340-6.

[16] Phisitkul P, McKinley TO, Nepola JV, et al. Complications of locking plate fixation in complex proximal tibia injuries. J Orthop Trauma 2007;21(2):83-91.

[17] Waddell JP, Johnston DW, Neidre A. Fractures of the tibial plateau: a review of ninety five patients and comparison of treatment methods. J Trauma 1981;21(5):376-81.

[18] Yu Z, Zheng L, Zhang Y, et al. Functional and radiological evaluations of high energy tibial plateau fractures treated with double-buttress plate fixation. European Journal of Medical Research 2009;14(5):200-5.

[19] Zeng ZM, Luo CF, Putnis S, et al. Biomechanical analysis of posteromedial tibial plateau split fracture fixation. The Knee 2011;18(1):51-4.

[20] West JR, Mutty CE, Ehrensberger MT. Biomechanics of posterior plating and screw fixation of posteromedial fragment in tibial plateau fractures. johnwest@buffalo.edu. Poster No. 1522 - ORS 2011. www.ors.org/Transactions/57/1522.pdf 